\title{
TRANSLUCENT COMPONENT TO PROVIDE THERMAL ENERGY SAVING IN BUILDINGS
}

\author{
Kristina Lebedeva, Galina Kashkarova, Andrejs Snegirjovs, \\ Peteris Shipkovs, Martins Vanags \\ Institute of Physical Energetics, Latvia \\ shipkovs@edi.lv
}

\begin{abstract}
The paper presents a study based on the perceived need to increase the building performance and quality of indoor comfort conditions, reduction of the unnecessary $\mathrm{CO}_{2}$ emissions and superfluous costs. In Europe, on average the consumption of energy in buildings constitutes $40 \%$ of the total consumption of energy. Approximately $70 \%$ of the consumed energy is used for heating and cooling houses. The physical characteristic transparent or translucent building components like windows are the weakest elements of the building envelope. Their $U$ value is usually 4 times higher than for opaque ones causing a considerable increase of heat loss during winter. In summer relatively high solar transmittance is a source of undesirable heat gains which result in overheating. The main reason for investigation of transparent building components is the very low heat saving capacity of such building components. During the whole year the radiant asymmetry close to the window surface influences thermal comfort. On the other hand, glazing elements are necessary in buildings to provide the required amount of daylight, preferably in a diffuse form. The specific challenge of the paper is development of new phase change material (PCM) glazing components for better building energy performance. The goal could be achieved by improving the heat capacity and heat transfer coefficient of transparent components by phase change materials application. The effect of latent heat storage of solar energy will result in an effective heat transfer coefficient and in this way PCM use helps ensure the level of comfort indoors. The novelty in investigation of the PCM glazing components will be introduced by taking into account as the main the following aspects - investigation of heat exchange processes in the PCM layer during energy storage and heat exchange by convection and radiation as well as determination of real performance of PCM glazing components under different weather conditions and, of course, practical construction solution of components including their movability.
\end{abstract}

Keywords: translucent building components, phase change materials, indoor microclimate.

\section{Introduction}

Many countries have already significantly reduced their total energy use per unit of GDP over the last three decades. The decline in energy intensity has been driven largely by improved energy efficiency in key end-uses, such as vehicles, appliances, space heating and industrial processes. Governments have implemented a wide range of policies and programs, such as energy efficiency standards, educational campaigns, obligations for market participants and financial incentives to accelerate the development and adoption of energy efficiency measures [1]. In this way, policies and programs have helped improve energy efficiency in the world, and continue to develop technologies in response to rising energy prices and increased competition in the different energy sectors. In all climatic conditions, it is very important to increase energy efficiency in buildings, because in warm climate zones a high amount of energy is required for conditioning, but in cold climate zones for heat supply.

Usually the studies and applications on energy efficiency in buildings have focused on the "opaque" part of building envelopes, such as walls, ceilings, and floors. However, we should notice one fact: generally speaking, the "transparent" part of the building envelopes, i.e. a window, has much lower thermal resistance than the other parts of the envelopes [2].

From the thermal point of view, windows represent the weak link between the internal and external ambient zones of a room. In cold climatic zones, they are the reason of 10-25\% of the heat losses from the heated ambient to the external atmosphere [3]. It should be pointed that the energy efficiency measures should not only increase the energy efficiency of buildings, but also maintain an appropriate microclimate in their premises.

Currently, there are commercially available types of glazing, such as Delta®-Cool 28 or GlassX® that incorporate PCM (PCM incorporated in the GlassX products is comprised of $\mathrm{CaCl} 2 \cdot 6 \mathrm{H} 2 \mathrm{O}$ salt hydrates that are completely sealed in clear polycarbonate) [4]. The products have a latent thermal storage of up to $4268 \mathrm{~kJ} \cdot \mathrm{m}^{-2}$, meaning that a period of $8 \mathrm{~h}$ passes before heat is transmitted [5]. 
The paper describes an opportunity to develop a new type of a glazing unit modified by the phase change material with the goal to improve thermophysical characteristics of the window component as an effective and unique type of the solar thermal energy storage system.

The idea of refining thermophysical properties of glazing components, e.g. windows by PCM application is relatively brand new. However, some experimental and simulation analysis have been done up to now.

This concept of the PCM filled window system is viable and thermally effective. The PCM filling leads to filtering out the thermal radiation and reduces the heat gain or losses because most of the energy transferred is absorbed during the phase change of the PCM. It means that the double glass window filled with PCM is more thermally effective than the same window filled with air [2].

\section{Investigation in the optimal location of PCM in the glazing component}

It was assumed that for the Latvian climate conditions triple glazing should be applied and one of the cavities will be filled with PCM, while the second one will work as thermal insulation. It means that there are two possible arrangements, as shown in Figure 1.
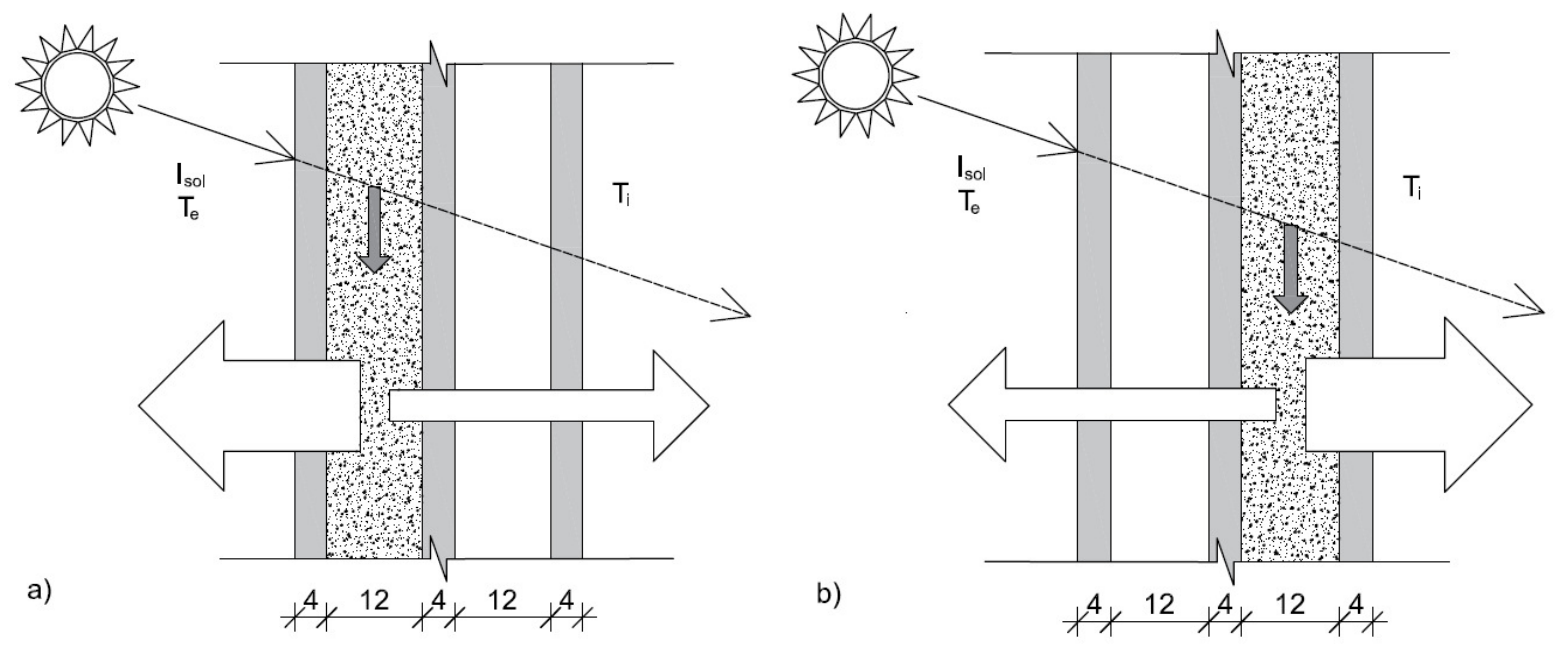

Fig. 1. Two possible arrangements of PCM glazing in Riga:

a - PCM located closer to outside, $b$ - PCM located closer to inside

The main goals of PCM application in the glazing component were to:

- reduce the heating energy demand by effective utilization of solar energy - increase of solar heat gains,

- reduce the cooling energy demand by reduction of solar heat gains.

Based on the preliminary analysis it was stated the following.

- For summer conditions PCM should be placed in a cavity located from outside (Figure 1. a). In that period PCM will play a role of dynamic insulation by storing solar energy during a period of substantial solar heat gains. In that case the active layer (PCM) is located in a distance from indoor environment. The inner cavity limits the heat transfer from the PCM layer to the room. During the night, when the external temperature drops down below the solidification point, the heat will be released into external environment by conduction and radiation. Additionally, in a solid state the material is characterised by lower solar transmittance what will additionally contribute to reduction of solar heat gains.

- For winter conditions PCM should be placed from inside (Figure 1. b.) filling the inner cavity, while the outer cavity will play a role of additional transparent insulation. Such kind of the component is characterised by high transmittance of solar radiation and good thermal insulation. In that case PCM layer will work as a collector of solar energy. Energy will be absorbed, converted into heat and stored during a period of high solar radiation (during a day), when the material temperature exceeds both external and internal ones. When the material is fully melted, its solar transmittance increases rapidly and subsequent amount of solar radiation 
will be utilised directly in the room. The heat stored in the active layer will be easily transferred into internal environment (by radiation and convection) and released during night hours. The physical mechanism is similar to low temperature surface heaters, but in that case the heat source is solar energy - on-site system.

\section{Building energy performance}

\section{Climate data}

External temperature in Riga in 2017 (Fig. 2) varied from $-19.2{ }^{\circ} \mathrm{C}$ to $32.6{ }^{\circ} \mathrm{C}$. reaching the minimum value in January and maximum in August. Average external temperature in Riga was $6.56^{\circ} \mathrm{C}[6]$.

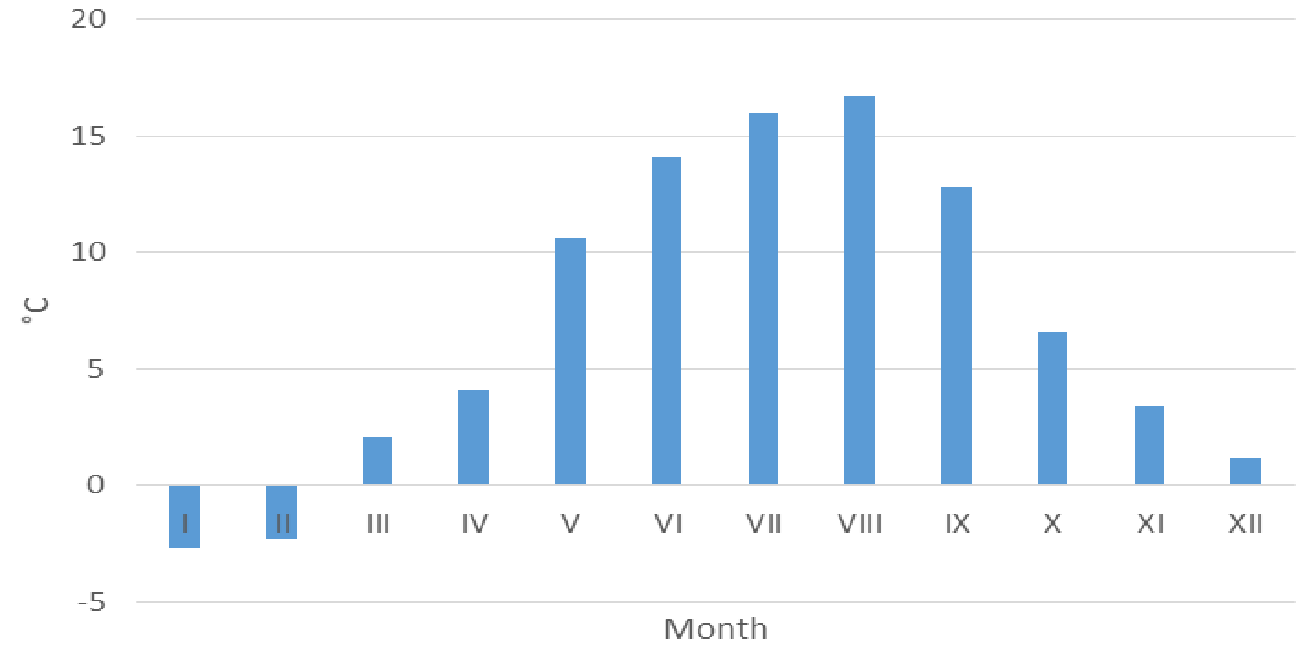

Fig. 2. Average external temperature, ${ }^{\circ} \mathrm{C}$

Quite big variance between minimum and maximum of external temperature determines the need for windows better quality of specific characteristics with the purpose to achieve energy savings.

\section{Heating/cooling system analysis}

In Latvia and Europe wide facilities for maintaining the optimal microclimate are actual, for what enormous energy resources are spent each year. Indoor temperature mostly affects space heaters and passive solar radiation that enters inside through the supporting construction.

As in the Latvian climatic conditions in the summer period (May-September) the average outside air temperature is about $15^{\circ} \mathrm{C}$, max daily temperature is from $+15^{\circ} \mathrm{C}$ till $+23^{\circ} \mathrm{C}$ (max temperature of summer season average value $+32.2^{\circ} \mathrm{C}$ ) and average solar radiation $-1100 \mathrm{kWh}$ per year [6].

Cooling is necessary 3000-5000 degree hours in the Baltic States climate conditions, but heating is necessary about 90000 degree hours. The heating season starts at the daily average outdoor air temperatures below $+8^{\circ} \mathrm{C}$. But cooling may be required already at low outdoor air temperature and high solar radiation. While temperature is about from +8 to $+16^{\circ} \mathrm{C}$, mostly neither heating nor cooling are needed [7].

\section{Selection of optimal phase change temperature}

Due to the assumption that during the heating season the internal temperature should be no less than $20^{\circ} \mathrm{C}$ and during the cooling season no more than $26^{\circ} \mathrm{C}$, it was stated that optimal phase temperatures will be always one degree above (for winter) and below (for summer) the set point. Assuming ideal control of the air conditioning system it will prevent loading PCM (melting or solidification) with the heat from the building system.

- $21^{\circ} \mathrm{C}$ (melting temperature) - during the heating season. 1 degree above the heating set point will allow to effectively store even little amount of winter solar radiation to keep the surface temperature higher than in traditional glass panes. 
- $25^{\circ} \mathrm{C}$ (solidification temperature) - during the cooling season. 1 degree below the cooling set point will allow to keep the indoor temperature in a comfort range while the cooling system is still not activated.

Based on the research with our project partners from Lodz University of Technology (Poland), Instituto de Investigaciones en Energía No Convencional (Argentina) and Pontificia Universidad Católica de Chile (Chile) using the modelling programs "ESP-r" and "EnergyPlus" it was decided to use Rubitherm ${ }^{\circledR}$ Technologies GmbH phase change material - RT18HC.

\section{Measurements of PCM thermophysical properties}

The chapter "Measurements of PCM thermophysical properties" of this paper is based on "SOLTREN Internal Report. Workpackage 1". The paraffin RT18HC thermophysical properties, such as the transition temperature and latent heat of phase change, were measured. Temperatures and heat flows associated with transitions in PCM samples were measured by the Differential Scanning Calorimetry (DSC) technique. Using the DSC it was possible to determine the temperature and heat flow associated with the material physical state transitions as a function of time and temperature. This technique also provides quantitative and qualitative data on endothermic (heat absorption) and exothermic (heat release) processes of materials during physical transitions that are caused by phase changes, melting, oxidation, and other heat-related changes.

All experiments were performed under the same algorithm (or program). Firstly, all samples were stabilized at $-5^{\circ} \mathrm{C}$. It is useful in order to mark an initial process temperature as reference. Then heated until $50^{\circ} \mathrm{C}$ and finally cooled until $-5^{\circ} \mathrm{C}$ again. $\mathrm{A} \pm 10^{\circ} \mathrm{C} \cdot \mathrm{min}^{-1}$ ramp was used for all process. Nitrogen consumption was configured at $10 \mathrm{ml} \cdot \mathrm{min}^{-1}$.

The method and selected cycles are described as following:

1. Equilibrate at $-5.00{ }^{\circ} \mathrm{C} ; 2$. Isothermal for $1.00 \mathrm{~min}$; 3. Mark end of cycle $1 ; 4$. Ramp $10.00^{\circ} \mathrm{C} \cdot \mathrm{min}^{-1}$ to $50.00^{\circ} \mathrm{C}$; 5. Isothermal for $2.00 \mathrm{~min}$; 6 . Mark end of cycle $2 ; 7$. Ramp $10.00{ }^{\circ} \mathrm{C} \cdot \mathrm{min}^{-1}$ to $-5.00{ }^{\circ} \mathrm{C} ; 8$. Isothermal for $1.00 \mathrm{~min}$; 9. Mark end of cycle 3 .

Time duration of each test was 14.83 minutes (Fig. 3). For individual sets of experiments around $10 \mathrm{mg}$ of RT18HC PCM was used.

Amount of PCM: $11.02 \mathrm{mg}$. Maximum instantaneous heat flow: $59.25 \mathrm{~mW}$, at $10.63^{\circ} \mathrm{C}$ (cooling) (Fig.4). Minimum instantaneous heat flow: $-54.43 \mathrm{~mW}$, at $21.07^{\circ} \mathrm{C}$ (heating) (Fig.4).

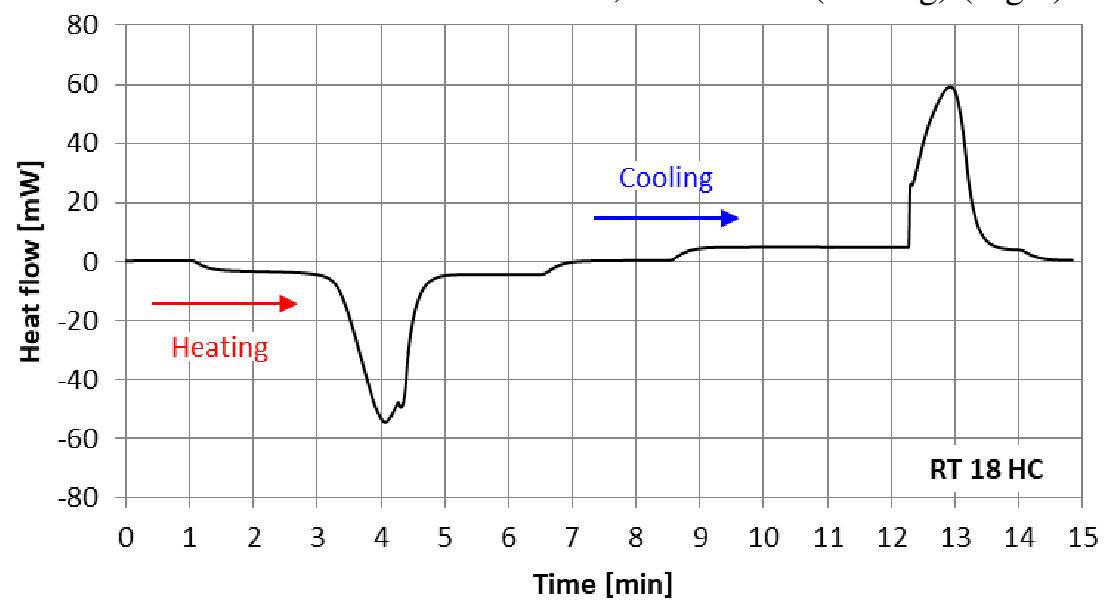

Fig. 3. Latent heat flow versus time during melting (lower line) and solidification (upper line) processes for paraffin RT18HC 


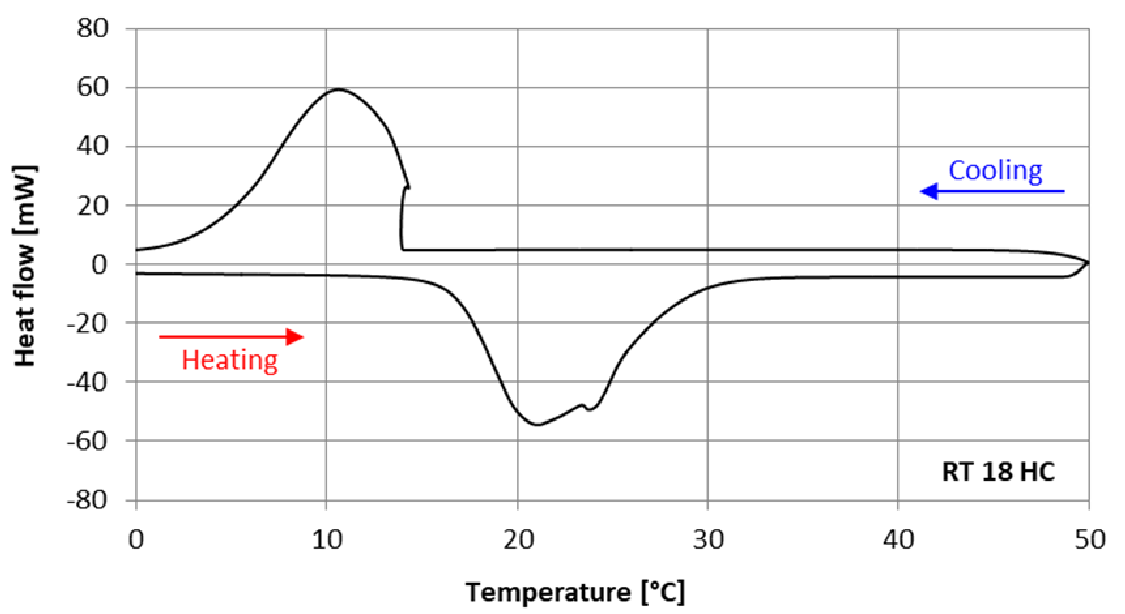

Fig. 4. Latent heat flow versus temperature during melting (lower line) and solidification (upper line) processes for paraffin RT18HC

\section{Result analysis and comments}

The results obtained from the DSC measurement were analyzed taking into account the most important two features for future applications: latent heat of the phase change and overcooling effect. The results are presented in Table 1.

Table 1

RT18HC measured parameters

\begin{tabular}{|c|c|c|c|}
\hline Latent heat, $\mathbf{J}^{-\mathbf{g}^{\mathbf{1}}}$ & Overcooling, $\mathbf{K}$ & $\begin{array}{c}\text { Maximum } \\
\text { solidification heat } \\
\text { flow, } \mathbf{~ m W}\end{array}$ & $\begin{array}{c}\text { Minimum melting } \\
\text { heat flow, } \mathbf{~ m W}\end{array}$ \\
\hline 260.60 & 10.44 & 59.3 & -54.4 \\
\hline
\end{tabular}

RT18HC types seem to be optimal where high energetic values are demanded due to their higher values of heat flows $(\mathrm{mW})$.

Latent heat was estimated based on the heat flow course versus temperature.

Overcooling: it should be concluded that the average value of overheating above $8 \mathrm{~K}$ can lead to delay in energy release by PCM-glazing. On the other hand, this triggers the effect of late solidification and keeps the material in liquid state (transparent) during the first period of cooling.

The minimum melting and maximum solidification heat flows were obtained for PCM during the heating process, while maximum solidification during the cooling process. The values are providing the information not only about the ability to store/release energy, but also about the maximum heat flow at specific temperature. It can be interpreted as a maximum heating power, which can be stored or released by PCM.

The interior surface temperature of the window in summer and winter for all the windows filled with PCM and air was modelled. Firstly, these results show that all peaks of the internal window surface temperatures filled with PCM are delayed in comparison with the window filled with air. This effect is due to the difference between the specific heat of the air and PCM [8]. RT18HC paraffin in some days in summer was always in liquid state, because the temperature in the window was at least $20{ }^{\circ} \mathrm{C}$ approximately. But in other days it changed every day, keeping the internal surface temperature constant near to the melting temperature during all working hours. During winter, PCM RT18HC is able to keep the internal temperature near to the melting temperature. To ensure the correct behaviour of the PCM glazing, it is needed that the phase change occurs every day. In the morning, PCM must change to liquid state, and at night it must change to solid state.

Thermal comfort is evaluated in terms of the Predicted Mean Vote (PMV) (IS0-7730:2005), a mathematical model of a thermal scale that runs from Cold $(-3)$ to Hot $(+3)$, which describe the thermal sensation of occupants [8]. All peaks of the internal window surface temperatures filled with 
PCM are delayed in comparison with the window filled with air, because they have different specific heat.

Table 2

PMV results

\begin{tabular}{|l|c|c|}
\hline Window filling & Summer & Winter \\
\hline Air & 1.0 & 1.1 \\
\hline RT18HC & 0.8 & 0.9 \\
\hline
\end{tabular}

Table 2 shows PMV for the temperature peaks for winter and summer. It shows that the PMV for the window filled with air is above or very close to 1.0 , which means the indoor microclimate is slightly hot. On the other hand, the PMV value less than 1.0 indicates comfortable microclimate.

The window filled with RT18HC allows achieving comfortable office indoor environment, because the PMV values are below 1.0.

Future studies are needed in order to evaluate the thermal stability of indoor microclimate, where PCM materials are used in windows.

\section{Conclusions}

The integration of PCM into translucent building components takes the advantage of latent thermal energy storage for additional energy savings. The development of energy - storing building components is a solution for improving the thermal comfort of internal building microclimate. Regarding the thermal comfort, it is expected that the indoor microclimate, where PCM materials are used in translucent building components, will be of significantly lower average radiation temperature, because the RT18HC filling reduces the inner surface temperature of the windows between $0^{\circ} \mathrm{C}$ and $10^{\circ} \mathrm{C}$ and of higher thermal stability, which is less likely overheating and lower temperature fluctuations.

\section{Acknowledgements}

This work is supported by the ERA-NET-LAC project Nr. ES RTD/2017/6 „Solar hybrid translucent component for thermal energy storage in buildings" (SOLTREN).

\section{References}

[1] World Energy Perspective. World Energy Council, 2013, ISBN: 978094612 126 7, 20 p.

[2] Socaciu L.G. Thermal Energy Storage with Phase Change Material. Leonardo Electronic Journal of Practices and Technologies, Issue 20, ISSN 1583-1078, January-June 2012, 75-98 pp.

[3] Kamal A.R. Ismail, Carlos T. Salinas, Jorge R. Henriquez. Comparison between PCM filled glass windows and absorbing gas filled windows. Energy and Buildings 40 (2008) 710-719 pp.

[4] Fokaides P.A., Kylili A., Kalogirou S.A. Phase change materials (PCMs) integrated into transparent building elements: a review. Mater Renew Sustain Energy (2015) 4:6, DOI 10.1007/s40243-015-0047-8, 13 p.

[5] GlassX North America. GlassX's website, Home. [online] [11.01.2019] Available at: http://www. glassxpcm.com/.

[6] State Ltd "Latvian Environment, Geology and Meteorology Centre", [online] [11.01.2019] Available at: http://www.meteo.lv/.

[7] Shipkovs P., Kashkarova G., Lebedeva K., 2009. Solar energy use for sustainable development, Proceedings of 29th ISES Biennial Solar World Congress 2009, South Africa, pp. 1881-1887.

[8] Uribe D., Benavente N., Bustamante W., Vera S. Numerical thermal model of a double-glazed window filled with phase change materials. 7th International Building Physics Conference, IBPC2018, Syracuse, NY, USA, pp. 1233-1238. 